\title{
PANDOLFO, Stefania. Knot of the soul: madness, psychoanalysis, Islam. Chicago: The University of Chicago Press, 2018. $384 \mathrm{p}$.
}

Camila Motta Paiva*

*Universidade de São Paulo - Ribeirão Preto, SP, Brasil

Doutoranda em Psicologia

camilapaiva@usp.br

https://orcid.org/0000-0002-1959-182X 
Ao abrir a Introdução com uma epígrafe de Lacan, uma de al-Ghazali, um trecho da fala de um imã e de um paciente psiquiátrico, Stefania Pandolfo já sinaliza a polifonia que irá reverberar nesse seu novo livro. Antropóloga professora da University of California Berkeley, Pandolfo se dedica há décadas ao estudo de teorias da subjetividade e da crítica decolonial em contextos árabe-islâmicos, mais especificamente direcionados ao Magrebe. Após estudar memória, trauma e perda em comunidades sul-marroquinas em sua investigação etnográfica anterior (Pandolfo, 1997), nessa obra recém-lançada ela empreende uma "tentativa de entender a experiência da loucura por meio de uma etnografia" (p. 2, tradução minha). Mais uma vez aprofundando-se no cenário marroquino, Pandolfo coloca a antropologia, a psicanálise e a teologia islâmica para dialogar - e eis que o resultado não é apenas extremamente interessante, mas também surpreendente pela originalidade.

Nessa etnografia multissituada, Pandolfo descreverá, na primeira parte do livro, o hospital psiquiátrico e centro de formação Razi, localizado na cidade de Salé, noroeste do Marrocos, etnografado por ela de 1998 a 2003. É nessa parte, "Fragmentos psiquiátricos no rescaldo da cultura", que a autora nos introduzirá às narrativas de alguns pacientes marcantes, bem como a diversos discursos de médicos psiquiatras com os quais ela teve contato ao longo desse percurso. A Parte II, "A passagem: imaginação, alienação", que é a mais breve e funciona como um interlúdio, trará ao leitor experiências da "loucura" que foram vividas por outros personagens dessa pesquisa, fora do contexto hospitalar. Por fim, na Parte III, "A jurisprudência da alma", a mais longa e mais complexa, Pandolfo entrará em discussões teológicas/epistemológicas islâmicas, que emergem sobretudo pelo profícuo diálogo estabelecido entre a autora e o imã, autoridade religiosa com quem ela dialoga desde 2005. Essa parte pode apresentar dificuldades para o leitor leigo em Islã (e até mesmo para os experientes), visto que adentra reflexões sobre a natureza da alma e traz referências clássicas em estudos islâmicos como Ibn Sina, al-Ghazali, Ibn Arabi e Ibn Khaldun. É também nesta parte final que o imã apresenta a Pandolfo o ritual da ruqya como uma proposta de cura dentro dos preceitos religiosos. ${ }^{1}$

1 Consultar Rassool (2016) para mais informações sobre a ruqya e outras práticas religiosas islâmicas relacionadas à saúde/cura. 
No capítulo 1, além de descrever o hospital Razi, somos apresentados à Amina. Trabalhadora de uma plantação de laranjas, fora acusada pelo marido em sua noite de núpcias de não ser mais virgem, uma acusação não apenas pesada, mas potencialmente destruidora nesse contexto. A paciente inicia uma jornada em busca de atestados de virgindade e relatórios médicos e judiciais que colocam seu corpo - e sua mente - à prova. Junto a Pandolfo, Amina começa a cantar para dar vazão às suas questões íntimas e a autora narra sua história para mostrar que a doença, a dor e o sofrimento vão além da validação e da padronização que muitas vezes a excessiva racionalidade médica impõe. A equipe médica tem a consciência de que o hospital costuma ser a última opção de cuidado procurada quando há alguma questão latente em saúde mental: sabe-se que os pacientes buscam em primeiro lugar as assim chamadas "terapias tradicionais", aquelas que fazem parte da tradição cultural-religiosa dessas pessoas. Tais terapias se relacionarão às concepções de saúde e de cura que se fazem presentes na cultura magrebina, bem como à proteção simbólica inerente a elas.

A mudança de paradigma na saúde mental no contexto marroquino é mais bem descrita no capítulo 2 , por meio do decreto real que no fim da década de 1950 instituiu as diretrizes da psiquiatria no país, regulando os períodos e as práticas de hospitalização e estabelecendo protocolos que visavam à proteção do paciente e dos seus direitos. Essas metas foram consideradas avançadas para aquela época, mas ainda hoje não foram plenamente atingidas, como o estabelecimento de centros de atenção à saúde mental em todas as províncias, especialmente em regiões periféricas e rurais. Além disso, a intervenção praticada no campo da saúde mental segue sendo majoritariamente emergencial: o hospital Razi é uma das apenas quatro escolas de psiquiatria do Marrocos e, para que atingisse um "padrão internacional", um modelo científico biologicista foi adotado em detrimento das práticas culturais que sempre circularam fortemente no país.

Sobre isso, entra-se no capítulo 3: os jinns. Os jinns, gênios, são descritos no Alcorão como seres invisíveis criados por Deus a partir do fogo. Através da narrativa da paciente Hind, Pandolfo apresenta essa esfera da crença cultural segundo a qual tais criaturas seriam capazes de se incorporar nos seres humanos, gerando assim doenças. Jinns seriam, nessa perspectiva, a doença "personificada" por meio da sua atuação como um "duplo". 
No capítulo 4 outra história é contada, a do jovem Reda, que considera a mãe como uma ignorante por ser iletrada. Por isso, opta por falar em francês com a equipe médica, a língua que ele atribui ao saber e à modernidade, em detrimento do árabe e do berbere que seriam os idiomas que marcariam o discurso religioso e folclórico. Pandolfo faz a crítica decolonial, que lhe é tão importante, ao notar que usualmente os pacientes chegam ao hospital falando árabe ou berbere, mas os prontuários ainda hoje são redigidos em francês, uma das marcas do legado colonial do país. Vê-se que a tradução não se reduz apenas à língua: é preciso traduzir a todo momento o vocabulário médico, o vocabulário popular, o vocabulário cultural-religioso.

Para fazer a transição entre a Parte I e a Parte II, Pandolfo abre um capítulo especial sobre o "Islã e a ética da psicanálise" para narrar uma experiência vivida no consultório de um amigo psicanalista. Na ocasião, buscava-se discutir as dificuldades da inserção da psicanálise nos contextos árabe-islâmicos, por esta ser geralmente entendida como excessivamente "ocidental" e elitista. ${ }^{2}$ É gratificante reconhecer o esforço magistral de Pandolfo para associar a psicanálise à saúde mental em uma perspectiva social e cultural, que ultrapassa a dimensão clínica. Do primeiro ao último capítulo do livro, a autora recorre às diversas teorias psicanalíticas, especialmente as postuladas por Freud e Lacan, não para necessariamente explicar os fenômenos que ela percebe em campo, mas para constantemente fazer uma aproximação entre psicanálise-antropologia-religião, que se mostra como possível e enriquecedora. Pandolfo indica que em um campo complexo e cheio de nuances, como é a saúde mental em uma perspectiva cultural-religiosa, não há como se ater apenas a um saber restrito: é preciso estar disposto a ampliar o olhar e estabelecer pontes entre as diversas disciplinas. Ao dar atenção à visão psicanalítica que por vezes é ignorada no campo da saúde mental, a autora evidencia que não há uma ruptura entre psicanálise e religião e também não há impedimentos de se beber da fonte psicanalítica em uma etnografia.

Entra-se na Parte II, breve, composta pelos capítulos 5 e 6. No capítulo 5 temos acesso a Samia, que convida a autora a conhecer as pinturas de seu companheiro Ilyas, imagens que expressam o que emerge do seu inconsciente.

2 Para um aprofundamento da história da psicanálise no contexto magrebino, ver Bennani (2008). 
Entre cobras, sereias e árvores, destacam-se as concepções diferentes desse casal sobre a doença. Ainda sobre histórias de vida e contrastes, Pandolfo nos apresenta no capítulo 6 a Kamal e Jawad, que ao fazerem uma reflexão sobre a necessidade de migração, de arriscar a vida em busca de algo que acreditam ser melhor, vão se engajar em uma discussão sobre algumas questões sociais relevantes, como a pobreza, o desemprego, o abandono social, a falta de garantia de direitos, a exclusão política e a falta de perspectiva para o futuro.

Encerrada essa problematização, entra-se na Parte III, "A jurisprudência da alma", em que os capítulos se tornam mais fragmentados, experimentais e ocasionalmente repetitivos. No capítulo 7, Pandolfo nos apresenta ao imã, o sábio religioso que se descreve como um especialista em doenças da alma. O imã repete um discurso muito frequente em campo islâmico, que é o de que a doença e a saúde, a facilidade e a adversidade, o prazer e a dor, a pobreza e a abundância, todos servem como testes e provações divinas com o propósito maior de cultivar as virtudes do coração.

Dos capítulos 8 a 11, a autora investe no detalhamento das dimensões da cura religiosa e da "medicina profética". O imã não nega a participação dos jinns no processo de doença, muito pelo contrário - afinal, do ponto de vista religioso, eles fazem parte da criação divina: são pertencentes ao ramo invisível e foram mencionados no Alcorão, o que não permitiria questionamento de sua existência. O que o imã rejeita é qualquer tipo de "negociação" que possa ser feita com essas criaturas, pois isso as revestiria de um poder que seria cabível apenas a Deus. Da mesma forma, o imã diz estar ciente de que a cura é sempre providenciada por Deus: o imã, por ser humano, é apenas um facilitador do processo curativo.

No capítulo 12, Pandolfo articula o discurso do imã e do Dr. A, o jovem residente que apresentou a autora ao líder religioso. Pandolfo valoriza a atitude do médico que, ao se deparar com questões que não estavam sendo respondidas em seu treinamento médico-científico, busca o imã para sanar suas dúvidas e melhor entender a natureza da doença mental do ponto de vista religioso, incluindo a agência secundária dos jinns no processo saúde-doença. A autora segue elaborando a reflexão de que não se trata de opor a cura médica e a cura baseada nas crenças religiosas/culturais: Pandolfo destaca que os outros médicos do hospital também buscavam estar atentos para não diagnosticar de imediato como "delirante" um paciente que alega ter entrado em contato ou ter 
sido possuído por um jinn. Os médicos sabem que, mesmo engajados no tratamento médico, a maioria dos pacientes segue realizando outras tentativas de cura fora do contexto médico-hospitalar. A ideia é que uma prática não necessariamente "briga" com a outra: podem assumir uma parceria para melhor responder às buscas da pessoa em sofrimento.

Do capítulo 13 ao capítulo 16, mais conceitos teológicos são discutidos com profundidade, especialmente o conceito de nafs. Para o imã, trata-se da dimensão da alma em relação com o coração, que é o centro do ser. Especialmente no capítulo 15, o imã afirma que não haveria como falar de depressão, por exemplo, sem falar dessa dimensão da alma. Recupera-se al-Ghazali e sua descrição das "aflições da alma" para chegar à batalha interna entre nossos desejos, paixões e vontades. Uma conclusão inicial é a de que para falar de saúde mental no contexto marroquino é preciso se aproximar da ciência, da religião e das práticas culturais, necessariamente. Para o imã, existe sim diferença entre a doença mental, a que seria estudada por psicólogos e psiquiatras, e as doenças da alma. Entretanto, elas também estariam relacionadas: a seu ver, as doenças mentais são majoritariamente causadas pelas doenças da alma.

Por fim, no capítulo 17, Pandolfo narra detalhadamente uma sessão de ruqya, uma performance-ritual de cura baseada na recitação de trechos alcorânicos que teriam efeitos no corpo e na alma da pessoa em sofrimento: a paciente deitada diante do imã, a recitação feita em nome de Deus e o lapso de consciência da mulher até chegar ao lamento do jinn e o acesso ao seu conteúdo. Quando desperta, a mulher pouco se lembra do que foi dito e feito, então o imã profere algumas palavras em forma de uma lição edificante acerca do episódio ali vivido.

A sensação ao finalizar o livro é a de que Pandolfo não negligenciou nenhum personagem social: todos os que compõem essa ampla rede relacionada à saúde mental em seus aspectos sociais, culturais e religiosos foram contemplados: pacientes, psicólogos, psicanalistas, psiquiatras, líderes religiosos. Pandolfo, mais do que dar voz, dá ouvidos a todos eles, deixando claro que não há uma fonte de conhecimento mais fidedigna do que outra: cada um pode partir do seu lugar de fala para expor seu entendimento sobre a saúde mental neste contexto.

Em determinado ponto do livro, Pandolfo havia sido questionada: "você sabe o que a loucura é?” (p. 171). Ao final, entende-se que a autora não busca 
dar respostas definitivas, nem aos seus interlocutores nem aos leitores. O que ela faz a todo momento é devolver a pergunta, implicitamente questionando a cada um: o que ela é para você, o que ela significa para cada voz. Dessa forma, a autora reconhece a todos como sujeitos, para muito além da subalternidade que por vezes é imposta aos que sofrem, exercendo a alteridade que é tão cara ao campo antropológico. Pandolfo faz um contraponto ao tradicional silenciamento que é feito em relação à experiência daqueles que sofrem e também da esfera cultural-religiosa nesse processo, geralmente considerada "menor" ou "menos válida" perante a assim chamada "ciência". Pandolfo garante a presença e a igual importância e pertinência dessas múltiplas vozes para 0 debate acerca da saúde mental, não negando a legitimidade dos seus discursos. Ao final, temos Knot of the soul como uma bem-vinda contribuição a esse campo pouco falado e pouco explorado, a saber: a interface entre saúde mental e a religião islâmica. Tem-se aí um campo instigante, vasto e ainda obscuro, especialmente no panorama de pesquisa brasileiro. Certamente, outros "nós" concernentes a essa temática podem e devem ser desatados em pesquisas e publicações futuras.

\section{Referências}

BENNANI, J. Psychanalyse en terre d'islam: introduction à la psychanalyse au Maghreb. Ramonville Saint-Agne: Éditions Érès, 2008.

PANDOLFO, S. Impasse of the angels: scenes from a Moroccan space of memory. Chicago: The University of Chicago Press, 1997.

RASSOOL, G. H. Islamic counselling: an introduction to theory and practice. New York: Routledge, 2016. 